\section{JURNAL EKONOMI EFEKTIF}

ISSN : $2622-8882$, E-ISSN : 2622-9935

Jurnal Ekonomi Efektif, Vol. 3, No. 4, Juli 2021

@Prodi Manajemen Fakultas Ekonomi Universitas

Pamulang

\title{
PENGARUH KEPEMIMPINAN TERHADAP KINERJA KARYAWAN PADA BPR WILAYAH SERANG BANTEN
}

\author{
Asep Saepulloh \\ Sekolah Tinggi Ilmu Ekonomi Dwimulya, Serang, Banten, Indonesia \\ saepullohasmi.7477@gmail.com*
}

\begin{abstract}
Manuskrip: Juni -2021 Ditinjau: Juni -2021; Diterima: Juni-2021; Online: Juli-2021; Diterbitkan: Juli-2021
\end{abstract}
\begin{abstract}
ABSTRAK
Penelitian ini bertujuan untuk mengetahui pengaruh kepemimpinan terhadap kinerja karyawan pada BPR wilayah Serang, Banten. Metode yang digunakan adalah explanatory research dengan sampel sebanyak 100 responden. Teknik analisis menggunakan analisis statistik dengan pengujian regresi, korelasi, determinasi dan uji hipotesis. Hasil penelitian ini variabel kepemimpinan diperoleh nilai rata-rata skor sebesar 3,414 dengan kriteria baik. Variabel kinerja karyawan diperoleh nilai rata-rata skor sebesar 3,841 dengan kriteria baik. Kepemimpinan berpengaruh positif dan signifikan terhadap kinerja karyawan dengan nilai persamaan regresi $\mathrm{Y}=9,323+0,852 \mathrm{X}$, dan nilai koefisien korelasi 0,777 atau memiliki tingkat hubungan yang kuat dengan nilai determinasi $60,3 \%$. Uji hipotesis diperoleh signifikansi 0,000 $<0,05$.
\end{abstract}

\section{Kata Kunci: Kepemimpinan, Kinerja Karyawan}

\begin{abstract}
This study aims to determine the influence of leadership on employee performance at BPR Serang, Banten. The method used is explanatory research with a sample of 100 respondents. The analysis technique uses statistical analysis with regression, correlation, determination and hypothesis testing. The results of this study of the leadership variable obtained an average score of 3,414 with good criteria. Employee performance variable obtained an average score of 3.841 with good criteria. Leadership has a positive and significant effect on employee performance with a regression equation value of $Y=9.323+$ $0.852 X$, and a correlation coefficient value of 0.777 or has a strong relationship with a determination value of $60.3 \%$. Hypothesis testing obtained a significance of $0.000<0.05$.
\end{abstract}

\section{Keywords: Leadership, Employee Performance}




\section{PENDAHULUAN}

\section{A. Latar Belakang}

Bank merupakan suatu lembaga yang mendapatkan izin untuk mengerahkan dana yang berasal dari masyarakat berupa simpanan dan menyalurkan dana tersebut kepada masyarakat yang berupa pinjaman, sehinggga bank berfungsi sebagai perantara antara penabung dan pemakai akhir, rumah tangga dan perusahaan.. Kurangnya komunikasi serta aneka ragam pengalaman berkenaan dengan likuiditas, risiko, waktu dan sebagainya, telah membuat hubungan langsung antara penabung dengan investor tidak efisien dan terbatas ruang lingkupnya (Ahmad, 2014).

Bank Perkreditan Rakyat yang biasa disingkat dengan BPR selalu melayani golongan pengusaha mikro, kecil dan menengah dengan lokasi pelayanan yang tidak melewati batas wilayah Kabupaten/Kota. Menghadapi persaingan di sektor perbankan yang semakin ketat, kepercayaan dari masyarakat merupakan salah satu kunci sukses yang mendorong kemajuan perusahaan (Dhammika, 2014). Sama seperti bank lainnya Bank Perkreditan juga harus diketahui kesehatannya. Kesehatannya bank dapat diartikan sebagai kemampuan suatu bank untuk melakukan kegiatan operasional perbankan secara normal dan mampu memenuhi semua kewajibannya dengan baik dengan cara-cara yang sesuai dengan peraturan perbankan yang berlaku (Marudut, 2014).

Sumber daya manusia dapat menentukan tingkat kinerja suatu bank selain analisa laporan keuangan BPR, sumber daya manusia yang disoroti pengembangannya dalam penelitian ini adalah sumber daya manusia karyawan BPR di Wilayah Serang, Banten, karena keberadaaanya sangat penting dalam memberikan peluang yang besar kepada masyarakat pedesaan untuk meningkatkan kesejahteraan hidupnya. Untuk menjamin kesinambungan perusahaan, perlu adanya perpaduan dari enam aspek faktor produksi (Fitria dan Djum, 2014) yaitu man, money, materials, methods, market, machine.

Beberapa penelitian menyimpulkan kinerja dalam menjalankan fungsinya tidak berdiri sendiri, tetapi berhubungan dengan peran kepemimpinan dan tingkat tingkat motivasi yang diberikan oleh perusahaan. Kepemimpinan merupakan kemampuan yang dimiliki seseorang untuk mempengaruhi orang-orang lain agar bekerja mencapai tujuan dan sasaran. Sehingga, sangat diperlukan teladan dari seorang pemimpin yang nantinya menjadi panutan bawahannya (Handoko dan Reksohadiprodjo, 2009:294).

Persaingan perbankan dan lembaga keuangan menyiratkan perlunya optimalisasi kinerja sumber daya manusianya pada Bank Perkreditan Rakyat (BPR) agar tetap bertahan. Dengan kata lain, untuk meningkatkan daya saing, maka berbagai macam faktor yang yang meningkatkan kinerja sumber daya manusianya perlu mendapat perhatian serius. Menurut Trotter (1986) dalam Sadia et al., (2015) mendefinisikan bahwa seorang yang kompeten adalah orang yang dengan keterampilannya mengerjakan pekerjaan yang mudah, cepat, intuitif dan sangat jarang atau tidak pernah membuat kesalahan. Ini menujukan bahwa karyawan harus memiliki kemampuan yang baik dalam menjalankan tugas-tugasnya agar hasil dari kinerja relevan dan handal.

Fenomena menyangkut rendahnya kinerja yang terjadi pada saat ini melalui hasil penilaian beberapa karyawan di BPR wilayah Serang yang digunakan sebagai sampel awal, diketahui karyawan dengan pengalaman kerja yang lama, karyawan senior, sering kurang mau mengikuti pelatihan, karena merasa sudah mampu menyelesaikan pekerjaan yang menjadi tanggungjawabnya, terlihat bahwa ada beberapa karyawan senior dalam hal ini adalah mereka yang memiliki pengalaman kerja sudah lama dalam arti kata telah bekerja lebih dari 3 tahun memiliki kinerja yang standar, tidak 
terlalu bagus dan juga tidak terlalu buruk, hal ini dapat dipengaruhi karena posisi mereka pada saat ini sudah mapan dan juga merupakan karyawan tetap. Namun yang menjadi perhatian adalah sedikitnya karyawan dengan pengalaman kerja yang cukup mau mengikuti pelatihan. Karyawan senior sebagain besar memiliki anggapan bahwa pelatihan hanya diperlukan bagi karyawan baru dan bukan merupakan bagian dari rencana kerja perusahaan dalam peningkatan kinerja. Hal ini sudah dianggap menjadi kebiasaan sehingga akan berdampak dalam mengurangi kinerja perusahaan secara umum (Ahmad, 2014).

Bank Perkreditan Rakyat (BPR) merupakan lembaga keuangan bank yang menerima simpanan hanya dalam bentuk deposito berjangka, tabungan, dan bentuk lainnya yang dipersamakan dengan itu dan menyalurkan dana sebagai usaha BPR. BPR perlu memperhatikan aspek-aspek untuk menilai tingkat kesehatan bank antara lain capital, asset quality, management, earning, dan likuiditas. Aspek-aspek ini ditetapkan berdasarkan kesepakatan internasional seperti yang telah ditetapkan oleh Bank of International Settlement (BIS).

Robbins \& Judge (2015:217) menyatakan kepemimpinan sebagai kemampuan yang dapat mempengaruhi suatu kelompok menuju pada pencapaian sebuah visi atau tujuan yang telah ditetapkan. Untuk sebuah perusahaan kepemimpinan merupakan faktor yang krusial, karena perusahaan membutuhkan nahkoda atau motor penggerak bagi anggotanya yang diharapkan akan berdampak baik bagi perusahaan ke arah yang lebih baik di setiap waktunya, salah satunya gaya kepemimpinan yang dibutuhkan untuk mencapai visi atau tujuan perusahaan sebagai pengerak bawahannya untuk melaksanakan pekerjaanya (Syaid, 2014).

Berdasarkan pemaparan di atas, maka penulis tertarik melakukan penelitian dengan judul "Pengaruh Kepemimpinan Terhadap Kinerja Karyawan BPK di Wilayah Serang Banten".

\section{B. Rumusan Masalah}

1. Bagaimana kepemimpinan pada BPR wilayah Serang, Banten ?.

2. Bagaimana kinerja karyawan pada BPR wilayah Serang, Banten ?.

3. Adakah pengaruh antara kepemimpinan terhadap kinerja karyawan pada BPR wilayah Serang, Banten ?.

\section{Tujuan Penelitian}

1. Untuk mengetahui kondisi kepemimpinan pada BPR wilayah Serang, Banten.

2. Untuk mengetahui kondisi kinerja karyawan pada BPR wilayah Serang, Banten.

3. Untuk mengetahui pengaruh kepemimpinan terhadap kinerja karyawan pada BPR wilayah Serang, Banten.

\section{TINJAUAN PUSTAKA}

\section{Kepemimpinan}

Kepemimpinan diperlukan oleh perusahaan dalam upaya pencapaian tujuan suatu organisasi. Karyawan dituntut untuk dapat mengikuti arahan dari pimpinannya karena merekalah yang dianggap mampu menjadi influence bagi karyawan untuk dapat memiliki tujuan yang sama dengan perusahaan. Jika tujuan yang dituju tidaklah sama maka akan sulit bagi suatu organisasi menjalankan proses pencapaiannya

Definisi kepemimpinan menurut Sudaryono (2019:8) "Kepemimpinan adalah setiap perbuatan yang ditentukan oleh individu atau kelompok untuk mengkoordinasi dan memberi arah kepada individu atau kelompok yang tergabung didalam wadah tertentu 
untuk mencapai tujuan yang telah ditetapkan sebelumnya“.

\section{Kinerja Karyawan}

Penilaian kinerja berguna untuk memperbaiki kinerja dimasa yang akan datang, memberikan nilai umpan balik tentang kualitas kerja untuk kemudian mempelajari kemajuan perbaikan yang dikehendaki dalam kinerja.

Menurut Mangkunegara (2019:75) pengertian kinerja adalah hasil kerja secara kualitas dan kuantitas yang dicapai oleh seorang pegawai dalam melaksanakan tugasnya sesuai dengan tanggung jawab yang diberikan kepadanya

\section{METODE PENELITIAN}

\section{Populasi}

Populasi dalam penelitian ini berjumlah 100 responden karyawan BPR wilayah Serang, Banten

\section{Sampel}

Teknik pengambilan sampling dalam penelitian ini adalah sampel jenuh, dimana semua anggota populasi dijadikan sebagai sampel. Dengan demikian sampel dalam penelitian ini sampel yang digunakan berjumlah 100 responden.

\section{Jenis Penelitian}

Jenis penelitian yang dipakai adalah asosiatif, dimana tujuannya adalah untuk mengetahui atau mencari keterhubungan antara variabel independen terhadap variabel dependennya

\section{Metode Analisis Data}

Dalam menganalisis data digunakan uji validitas, uji reliabilitas, analisis regresi linier sederhana, analisis koefisien korelasi, analisis koefisien determinasi dan pengujian hipotesis.

\section{HASIL PENELITIAN}

\section{Analisis Deskriptif}

Pada pengujian ini digunakan untuk mengetahui skor minimum dan maksimum skor tertinggi, ratting score dan standar deviasi dari masing-masing variabel. Adapun hasilnya sebagai berikut:

Tabel 1. Hasil Analisis Descriptive Statistics

Descriptive Statistics

\begin{tabular}{ll|r|r|r|r} 
& N & Minimum & Maximum & Mean & Std. Deviation \\
\hline Kepemimpinan (X) & 100 & 28 & 44 & 34.14 & 3.864 \\
\hline Kinerja Karyawan (Y) & 100 & 29 & 49 & 38.41 & 4.238 \\
\hline Valid N (listwise) & 100 & & & & \\
\hline
\end{tabular}

Kepemimpinan diperoleh varians minimum sebesar 28 dan varians maximum 44 dengan ratting score sebesar 3,414 dengan standar deviasi 3,864. Skor ini termasuk pada rentang sakala 3,40-4,19 dengan kriteria baik atau setuju.

Kinerja karyawan diperoleh varians minimum sebesar 29 dan varians maximum 49 dengan ratting score sebesar 3,841 dengan standar deviasi 4,238. Skor ini termasuk pada rentang sakala 3,40-4,19 dengan kriteria baik atau setuju.

\section{Analisis Kuantitatif}

Pada analisis ini dimaksudkan untuk mengetahui pengaruh variabel independen terhadap variabel dependen. Adapun hasil pengujian sebagai berikut:

\section{a. Analisis Regresi Linier Sederhana}

Uji regresi ini dimaksudkan untuk mengetahui perubahan variabel dependen 
jika variabel independen mengalami perubahan. Adapun hasil pengujiannya sebagai berikut:

Tabel 2. Hasil Pengujian Regresi Linier Sederhana Coefficients $^{\mathbf{a}}$

\begin{tabular}{|c|c|c|c|c|c|c|}
\hline \multirow{3}{*}{\multicolumn{2}{|c|}{ Model }} & \multicolumn{2}{|r|}{ Coefficients $^{\boldsymbol{a}}$} & \multirow{3}{*}{$\begin{array}{c}\text { Standardized } \\
\text { Coefficients } \\
\text { Beta } \\
\end{array}$} & \multirow[b]{3}{*}{$\mathrm{t}$} & \multirow[b]{3}{*}{ Sig. } \\
\hline & & \multicolumn{2}{|c|}{ Unstandardized Coefficients } & & & \\
\hline & & $\mathrm{B}$ & Std. Error & & & \\
\hline \multirow[t]{2}{*}{1} & (Constant) & 9.323 & 2.397 & & 3.889 & .000 \\
\hline & $\begin{array}{l}\text { Kepemimpin } \\
\text { an }(\mathrm{X})\end{array}$ & .852 & .070 & .777 & 12.209 & .000 \\
\hline
\end{tabular}

a. Dependent Variable: Kinerja Karyawan (Y)

Berdasarkan hasil pengujian pada tabel di atas, diperoleh persamaan regresi $\mathrm{Y}$ $=9,323+0,852 X$. Dari persamaan tersebut dijelaskan sebagai berikut:

1) Konstanta sebesar 9,323 diartikan jika kepemimpinan tidak ada, maka telah terdapat nilai kinerja karyawan sebesar 9,323 point.

2) Koefisien regresi kepemimpinan sebesar 0,852 , angka ini positif artinya setiap ada peningkatan kepemimpinan sebesar 0,852 point maka kinerja karyawan juga akan mengalami peningkatan sebesar 0,852 point.

\section{b. Analisis Koefisien Korelasi}

Analisis koefisien korelasi dimaksudkan untuk mengetahui tingkat kekuatan hubungan dari variabel independen terhadap variabel dependen. Adapun hasil pengujian sebagai berikut:

Tabel 3. Hasil Pengujian Koefisien Korelasi Kepemimpinan Terhadap Kinerja Karyawan. Correlations $^{\mathbf{b}}$

\begin{tabular}{llr|r} 
& & $\begin{array}{c}\text { Kepemimpinan } \\
(\mathrm{X})\end{array}$ & $\begin{array}{r}\text { Kinerja Karyawan } \\
(\mathrm{Y})\end{array}$ \\
\hline Kepemimpinan $(\mathrm{X})$ & Pearson Correlation & 1 & $.777^{* *}$ \\
\cline { 2 - 4 } & Sig. (2-tailed) & & .000 \\
\hline Kinerja Karyawan $(\mathrm{Y})$ & Pearson Correlation & $.777^{* *}$ & 1 \\
\cline { 2 - 4 } & Sig. (2-tailed) & .000 & \\
\hline
\end{tabular}

**. Correlation is significant at the 0.01 level (2-tailed).

b. Listwise $\mathrm{N}=100$

Berdasarkan hasil pengujian diperoleh nilai korelasi sebesar 0,777 artinya kepemimpinan memiliki hubungan yang kuat terhadap kinerja karyawan.

\section{c. Analisis Koefisien Determinasi}

Analisis koefisien determinasi dimaksudkan untuk mengetahui besarnya persentase pengaruh dari variabel independen terhadap variabel dependen. Adapun hasil pengujian sebagai berikut:

Tabel 4. Hasil Pengujian Koefisien Determinasi Kepemimpinan Terhadap Kinerja Karyawan.

\begin{tabular}{|c|c|c|c|c|}
\hline \multicolumn{5}{|c|}{ Model Summary } \\
\hline Model & $\mathrm{R}$ & R Square & $\begin{array}{l}\text { Adjusted R } \\
\text { Square } \\
\end{array}$ & $\begin{array}{l}\text { Std. Error of the } \\
\text { Estimate }\end{array}$ \\
\hline 1 & $.777^{\mathrm{a}}$ & .603 & .599 & 2.683 \\
\hline
\end{tabular}

a. Predictors: (Constant), Kepemimpinan (X)

Berdasarkan hasil pengujian diperoleh nilai determinasi sebesar 0,603 artinya kepemimpinan memiliki kontribusi pengaruh sebesar 60,3\% terhadap kinerja karyawan, sedangkan sisanya sebesar 39,7\% dipengaruhi oleh faktor lain yang tidak dilakukan penelitian. 


\section{d. Uji Hipotesis}

Pengujian hipotesis dengan uji t digunakan untuk mengetahui hipotesis mana yang diterima.

Rumusan hipotesis: Terdapat pengaruh yang signifikan kepemimpinan terhadap kinerja karyawan.

Tabel 5. Hasil Uji Hipotesis Kepemimpinan Terhadap Kinerja Karyawan. Coefficients $^{\mathrm{a}}$

Unstandardized

Coefficients

\begin{tabular}{|c|c|c|c|c|c|c|}
\hline \multirow{2}{*}{\multicolumn{2}{|c|}{ Model }} & \multicolumn{2}{|c|}{ 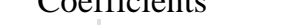 } & \multirow{2}{*}{ Beta } & \multirow[b]{2}{*}{$\mathrm{t}$} & \multirow[b]{2}{*}{ Sig. } \\
\hline & & $\mathrm{B}$ & Std. Error & & & \\
\hline 1 & (Constant) & 9.323 & 2.397 & & 3.889 & .000 \\
\hline & Kepemimpinan (X) & .852 & .070 & .777. & 12.209 & .000 \\
\hline
\end{tabular}

a. Dependent Variable: Kinerja Karyawan (Y)

Berdasarkan hasil pengujian pada tabel di atas, diperoleh nilai t hitung $>\mathrm{t}$ tabel atau $(12,209>1,984)$, dengan demikian hipotesis yang diajukan bahwa terdapat pengaruh yang signifikan atara kepemimpinan terhadap kinerja karyawan diterima.

\section{Pembahasan Hasil Penelitian}

\section{Kondisi Jawaban Responden Variabel Kepemimpinan}

Berdasarkan jawaban responden, variabel kepemimpinan diperoleh ratting score sebesar 3,414 berada di rentang skala 3,40-4,19 dengan kriteria baik atau setuju.

\section{Kondisi Jawaban Responden Variabel Kinerja Karyawan}

Berdasarkan jawaban responden, variabel kinerja karyawan diperoleh ratting score sebesar 3,841 berada di rentang skala 3,40 - 4,19 dengan kriteria baik atau setuju.

\section{Pengaruh Kepemimpinan Terhadap Kinerja Karyawan}

Kepemimpinan berpengaruh signifikan terhadap kinerja karyawan dengan persamaan regresi $\mathrm{Y}=9,323+0,852 \mathrm{X}$, nilai korelasi sebesar 0,777 atau memiliki hubungan yang kuat dengan kontribusi pengaruh sebesar 60,3\%. Pengujian hipotesis diperoleh nilai t hitung $>\mathrm{t}$ tabel atau $(12,209>1,984)$. Dengan demikian hipotesis yang diajukan bahwa terdapat berpengaruh signifikan antara kepemimpinan terhadap kinerja karyawan diterima.

\section{KESIMPULAN DAN SARAN}

\section{Kesimpulan}

a. Variabel kepemimpinan diperoleh ratting score sebesar 3,414 berada di rentang skala 3,40 - 4,19 dengan kriteria baik atau setuju.

b. Variabel kinerja karyawan diperoleh ratting score sebesar 3,841 berada di rentang skala 3,40 - 4,19 dengan kriteria baik atau setuju.

c. Kepemimpinan berpengaruh signifikan terhadap kinerja karyawan dengan persamaan regresi $\mathrm{Y}=9,323+0,852 \mathrm{X}$, nilai korelasi sebesar 0,777 atau kuat dan kontribusi pengaruh sebesar $60,3 \%$ sedangkan sisanya sebesar $39,7 \%$ dipengaruhi faktor lain. Uji hipotesis diperoleh nilai $t$ hitung $>t$ tabel atau $(12,209>1,984)$.

\section{Saran}

a. Pemimpin hendaknya memiliki integritas yang tinggi dan mampu menjadi suritauladan kepada bawahannya sehingga menambah kepercayaan karyawannya

b. Pimpinan harus mampu mengajarkan pekerjaan yang mampu diselesaikan tepat waktu 
dan memenuhi kuantitas yang ditentukan sehingga mencapai target perusahaan

\section{DAFTAR PUSTAKA}

Abdullah, M (2014) Manajemen dan Evaluasi Kinerja Karyawan, Yogyakarta: Penerbit Aswaja Pressindo.

Algifari. (2015). “Analisis Regresi untuk Bisnis dan Ekonomi”. Yogyakarta: BPFE.

Bangun, Wilson. 2012. "Manajemen Sumber Daya Manusia”. Jakarta: Erlangga

Barsah, A. (2019). Pengaruh Motivasi Dan Disiplin Terhadap Kinerja Pegawai Pada Dinas Kependudukan Dan Pencatatan Sipil Kota Tangerang. JENIUS (Jurnal Ilmiah Manajemen Sumber Daya Manusia), 3(1), 1-15.

Bejo Siswanto (2013) Manajemen Tenaga Kerja Rancangan dalam Pendayagunaan dan Pengembangan Unsur Tenaga Kerja", Bandung: Sinar Baru.

Dessler, G. (2006.) Manajemen Sumber Daya Manusia (Jilid II). Jakarta: Indeks. Edi Sutrisno (2016). Manajemen Sumber Daya Manusia. Jakarta: Prenadamedia Group. George Terry R \& Rue, Leslie W. Rue (2016) Dasar-Dasar Manajemen, Jakarta Bumi Aksara.

Gerry Dessler (2016) Human Resources Management, Prenticehall, London: International Inc.

Handoko (2016) Manajemen Personalia dan Sumberdaya Manusia. Yogyakarta: BPFE.

Hasibuan, Malayu S.P. (2016). Manajemen Sumber Daya Manusia. Edisi Revisi. Jakarta: PT Bumi Aksara.

Imam Ghozali (2017). “Aplikasi Analisis Multivariate Dengan Program SPSS”. Edisi Kelima. Semarang: Badan Penerbit Undip.

Istijanto (2014) “Riset Sumber Daya Manusia”. Jakarta: PT. Gramedia Pustaka

Kharis, Ismu Fadli (2011). "Studi Mengenai Impulse Buying dalam Penjualan Online”. Semarang : Skripsi Universitas Diponegoro

Luthans Fred (2014) Organizational Behavior, Ney York: McGraw-Hill, New York.

Mangkunegara, Prabu Anwar. (2016). Evaluasi Kinerja SDM. Cetakan ke tujuh, PT Refika Aditama: Bandung.

Salim, A. O., \& Rawi, R. D. P. (2020). Pengaruh Jaminan Sosial Tenaga Kerja Terhadap Produktivitas Kerja Karyawan Pada PT Sumber Abadi Indonesia Cabang Kota Sorong Papua Barat. Jurnal Ilmiah Manajemen Emor (Ekonomi Manajemen Orientasi Riset), 4(1), 32-40.

Sedarmayanti (2016) Manajemen Sumber Daya Manusia, Reformasi Birokrasi dan Manajemen Karyawan Negeri Sipil, Cetakan Kelima, Bandung: PT Refika Aditama. Sudjana (2014) “Metode Statistika”, Bandung: Tarsido.

Sugiyono (2017), "Metode Penelitian Administrasi : dilengkapi dengan Metode $R \&$ D”. Bandung: Alfabeta.

Sunarsi, D. (2017). Pengaruh Kepemimpinan Dan Budaya Organisasi terhadap Kinerja Karyawan Pada Cabang Pembantu Bank DKI Pondok Labu-Jakarta Selatan. JENIUS, 1(2), 21.

Sutrisno, S. (2019). Pengaruh Kepemimpinan Dan Disiplin Kerja Terhadap Kinerja Guru SMP Muhammadiyah 44 Pamulang. JENIUS (Jurnal Ilmiah Manajemen Sumber Daya Manusia), 3(1), 58-73.

Veithzal Rivai (2015) Manajemen Sumber Daya Manusia Untuk Perusahaan, Jakarta: Raja Grafindo Persada.

Wibowo (2015) Manajemen Kinerja, Jakarta: PT. Raja Grafindo Persada. 